\title{
Influence of Chemical Additives on the Properties of Composite Materials Based on Fine-Dispersed High-Calcium Fly Ash
}

\author{
Olga M. Sharonova*a, Valerii M. Kirilets ${ }^{a}$, \\ Leonid A. Solovyova and Alexander G. Anshits ${ }^{\mathrm{a}, \mathrm{b}}$ \\ ${ }^{a}$ Institute of Chemistry and Chemical Technology SB RAS \\ FRC "Krasnoyarsk Science Center SB RAS" \\ Krasnoyarsk, Russian Federation \\ ${ }^{b}$ Siberian Federal University \\ Krasnoyarsk, Russian Federation
}

\begin{abstract}
Composite materials (CM) were obtained on the basis of fine- dispersed high-calcium fly ash (HCFA), selected from the 4th field of electrostatic precipitators of Krasnoyarsk TPP-2, with the addition of Melflux 5581F superplasticizer at the water: binder ratio W/B $=0.25$. The influence of the concentration of superplasticizer in the range $0.06-0.6 \mathrm{wt}$. \% on the strength properties of composite materials was studied. The effect of the addition of sodium sulfate as an accelerator of hydration hardening and additives-retarders of sodium phosphate, sodium tetraborate and citric acid, were studied. The optimal concentration of superplasticizer was established (0.3 wt. \%). It was determined that sodium sulfate helps to improve the strength of $\mathrm{CM}$, and the addition of sodium tetraborate and citric acid can effectively regulate the setting time.
\end{abstract}

Keywords: composite material, high-calcium fly ash, superplasticizer, hardening accelerator, retarder.

Citation: Sharonova O.M., Kirilets V.M., Solovyov L.A., Anshits A.G. Influence of chemical additives on the properties of composite materials based on fine-dispersed high-calcium fly ash, J. Sib. Fed. Univ. Chem., 2020, 13(3), 395-407. DOI: $10.17516 / 1998-2836-0192$

(c) Siberian Federal University. All rights reserved

This work is licensed under a Creative Commons Attribution-NonCommercial 4.0 International License (CC BY-NC 4.0).

* Corresponding author E-mail address: sharon05@yandex.ru 


\title{
Влияние химических добавок на свойства
}

\section{композитных материалов на основе тонкодисперсной \\ высококальциевой летучей золы}

\author{
О.М. Шаронова ${ }^{\mathrm{a}}$, В.М. Кирилец ${ }^{\mathrm{a}}$, \\ Л.А. Соловьев ${ }^{\mathrm{a}}$, А.Г. Аншиц ${ }^{\mathrm{a}, \tilde{0}}$ \\ ${ }^{a}$ Институт химии и химической технологии СО РАН \\ ФИЦ «Красноярский научный иентр СО РАН» \\ Российская Федерация, Красноярск \\ ${ }^{6}$ Сибирский федеральный университет \\ Российская Федерация, Красноярск
}

Аннотация. Композитные материалы (КМ) получали на основе тонкодисперсной высококальциевой летучей золы (ВКЛЗ), отобранной с 4-го поля электрофильтров Красноярской ТЭЦ-2, с добавкой суперпластификатора Melflux 5581F при отношении вода : связующее $\mathrm{B} / \mathrm{C}=0.25$. Изучено влияние концентрации суперпластификатора в интервале 0.06-0.6 мас. \% на прочностные свойства композитных материалов, а также влияние добавки сульфата натрия в качестве ускорителя гидратационного твердения и добавок-замедлителей - фосфата натрия, тетрабората натрия и лимонной кислоты. Установлена оптимальная концентрация суперпластификатора (0.3 мас. \%). Определено, что сульфат натрия способствует улучшению прочности КМ, а добавки тетрабората натрия и лимонной кислоты позволяют эффективно регулировать время схватывания.

Ключевые слова: композитный материал, высококальциевая летучая зола, гидратация, суперпластификатор, ускоритель твердения, замедлитель твердения.

Цитирование: Шаронова, О.М. Влияние химических добавок на свойства композитных материалов на основе тонкодисперсной высококальциевой летучей золы / О.М. Шаронова, В.М. Кирилец, Л.А. Соловьев, А.Г. Аншиц // Журн. Сиб. федер. ун-та. Химия, 2020. 13(3). С. 395-407. DOI: 10.17516/1998-2836-0192

\section{Введение}

Функциональные добавки являются необходимыми компонентами в современных технологиях минеральных вяжущих материалов, бетонов и композитных материалов (КМ), изготавливаемых на основе портландцемента, для управления их реологическими, прочностными и другими свойствами. Согласно стандарту [1], по основному эффекту действия добавки классифицируют на пластифицирующие, водоредуцирующие, стабилизирующие, регулирующие подвижность, кинетику твердения (ускорители, замедлители), повышающие прочность, морозостойкость, коррозионную стойкость, расширяющие, а также добавки, придающие специальные свойства.

Важной вехой в развитии технологии бетонов служит разработка водоредуцирующих добавок, приводящих к эффективному диспергированию тонкодисперсных цементирующих компонентов в жидкой фазе без увеличения количества добавляемой воды. С применением тре- 
тьего поколения таких добавок - поликарбоксилатных суперпластификаторов (Polycarboxylate Ether Superplasticizers - PCE) - стало возможным изготавливать высокотехнологичные бетоны, такие как высокопрочные бетоны (прочность на сжатие 50-100 МПа), сверхвысокопрочные бетоны (UHPC) с прочностью на сжатие $>150$ МПа или самоуплотняющийся бетон (SCC) $[2,3]$. Механизм действия РСЕ основан на том, что карбоксильные группы (-СOOH) основной цепи полимера обеспечивают адсорбцию на поверхности зерен цемента, а боковые цепочки создают стерические помехи, предотвращая слипание тонкодисперсных частиц [3]. Адсорбционные характеристики суперпластификаторов отличаются для разных компонентов минералогического состава цементов. Более сильное влияние на адсорбцию РСЕ имеют алюминат $\mathrm{Ca}_{3} \mathrm{Al}_{2} \mathrm{O}_{6}$ и алюмоферрит $\mathrm{Ca}_{4} \mathrm{Al}_{2} \mathrm{Fe}_{2} \mathrm{O}_{10}$ по сравнению с силикатами кальция $\mathrm{Ca}_{3} \mathrm{SiO}_{5}$ и $\mathrm{Ca}_{2} \mathrm{SiO}_{4}$ [4].

Водорастворимые неорганические соли щелочных и щелочноземельных металлов применяют для ускорения твердения цемента и увеличения ранней прочности $[5,6]$. Это, например, $\mathrm{CaCl}_{2}, \mathrm{CaNO}_{3}, \mathrm{Na}_{2} \mathrm{CO}_{3}, \mathrm{Na}_{2} \mathrm{SiO}_{3}$ [7]. Из органических веществ к добавкам-ускорителям относятся формиат кальция $\mathrm{Ca}(\mathrm{HCOO})_{2}$, щавелевая кислота $\mathrm{C}_{2} \mathrm{H}_{2} \mathrm{O}_{4}$. Эффект воздействия связан, в первую очередь, с активацией реакции гидратации трехкальциевого силиката $3 \mathrm{CaO} \cdot \mathrm{SiO}_{2}$ :

$$
3 \mathrm{CaO} \cdot \mathrm{SiO}_{2}+\mathrm{zH}_{2} \mathrm{O} \circledast \mathrm{Ca}_{\mathrm{x}} \mathrm{Si}(\mathrm{OH})_{\mathrm{y}} \cdot \mathrm{nH}_{2} \mathrm{O}+(3-\mathrm{x}) \mathrm{Ca}(\mathrm{OH})_{2} \text {. }
$$

Механизм активации может быть обусловлен: 1) изменением состава поровых растворов, приводящего к увеличению растворимости компонентов вяжущего материала; 2) химическим взаимодействием с исходными компонентами вяжущего материала и с продуктами гидратации. Добавки с кристаллографическими характеристиками, близкими продуктам гидратации, служат центрами кристаллизации новообразованных фаз [7].

В ряде случаев необходимо применять добавки, замедляющие схватывание и твердение. Этими свойствами обладают многие органические вещества, например гидроксикарбоновые кислоты (винная, лимонная) и их соли, лигносульфонат кальция и неорганические вещества гипс, фосфаты (фосфат Na), бораты (бура) [6-8]. Механизм их действия проявляется через разные типы взаимодействия частиц вяжущего материала с водой - адсорбция, осаждение, комплексообразование и нуклеация. Например, действие добавок, замедляющих схватывание, таких как сахароза, цитрат Са, ЭДТА, объясняют адсорбцией их на продуктах гидратации, особенно на $\mathrm{Ca}(\mathrm{OH})_{2}$ и гидросиликатах кальция (C-S-H) . Замедлители более эффективны для цементов с низким содержанием алюминатов, так как алюминатная фаза цемента поглощает большое количество замедлителя. В связи с этим используют добавки гипса для связывания алюмината кальция в эттрингит, что сохраняет эффективность добавок замедлителей гидратации и твердения других фаз.

Летучие золы от промышленного сжигания углей, применение которых в качестве заместителя цемента в композитных бетонах становится все более масштабным [9, 10], значительно отличаются по фазово-минералогическому составу от цемента, а следовательно, действие химических добавок также может существенно отличаться.

Целью работы было установить влияние концентрации поликарбоксилатного суперпластификатора, а также влияние добавок активаторов и замедлителей гидратационного твердения на свойства композитных материалов на основе тонкодисперсной высококальциевой летучей золы (ВКЛЗ).

$$
-397-
$$




\section{Объекты и методы}

В качестве исходного материала для композитных образцов использовалась тонкодисперсная высококальциевая летучая зола (ВКЛЗ) от промышленного пылевидного сжигания низкозольного (11\%) бурого угля марки Б2 Канско-Ачинского бассейна при температуре 1400 $1500{ }^{\circ} \mathrm{C}$ в котлоагрегатах типа БКЗ-420 с жидким шлакоудалением на Красноярской ТЭЦ-2. Проба ВКЛЗ отобрана с 4-го поля электрофильтров (ЭФ) на установке с эффективностью улавливания $\geq 98 \%$. Методы исследования ВКЛ3, в частности распределение по размерам частиц, макроэлементный состав и морфология детально описаны ранее [11, 12]. Для сравнения приводятся характеристики цемента ПЦ 42.5 Н Красноярского цементного завода. В качестве добавок применяли поликарбоксилатный суперпластификатор Melflux 5581F и реактивы - сульфат натрия $\mathrm{Na}_{2} \mathrm{SO}_{4}$, фосфат натрия 12-ти водный $\mathrm{Na}_{3} \mathrm{PO}_{4} \cdot 12 \mathrm{H}_{2} \mathrm{O}$, тетраборат натрия $\mathrm{Na}_{2} \mathrm{~B}_{4} \mathrm{O}_{7}$, лимонная кислота $\mathrm{C}_{6} \mathrm{H}_{8} \mathrm{O}_{7}$.

Композитные образцы высокой прочности приготовлены из 100\% этой ВКЛЗ при отношении вода : связующее $\mathrm{B} / \mathrm{C}=0.25$ с добавкой $0.06,0.12,0.3$ и 0.6 мас. \% суперпластификатора Melflux 5581F в виде отвержденных кубиков 20х20х20 мм. Образцы хранили во влажной атмосфере в течение 1-120 сут. Испытания прочности образцов выполнены с помощью настольной двухколонной испытательной машины Instron модель 3360 (Instron, США), со скоростью движения траверса 5 мм/мин. Время схватывания определялось в соответствии с ГОСТ 310.3-76 на лабораторном приборе Вика.

Количественный фазовый анализ выполнен с применением полнопрофильного метода Ритвельда и минимизации производной разности, детали анализа приведены в [12]. Рентгенограммы снимали в геометрии на отражение с использованием Со К $\alpha$ излучения на дифрактометре PANalytical X'Pert PRO с детектором PIXcel и графитовым монохроматором. Сканирование рентгенограмм проводили в диапазоне углов дифракции $2 \theta=7-100^{\circ}$. Весовой процент кристаллической и аморфной компоненты определяли методом внешнего стандарта (использовали корунд). Коэффициенты поглощения образцов рассчитывали исходя из общего элементного состава по данным химического анализа.

Синхронный термический анализ (СТА) гидратированных образцов КМ после сушки в течение 2 ч при $60{ }^{\circ} \mathrm{C}$ выполнен на приборе Jupiter STA 449C («Netzsch», Германия) с массспектральным анализатором Aeolos QMS403C («Netzsch», Германия) в Pt-Rh-тиглях с крышкой

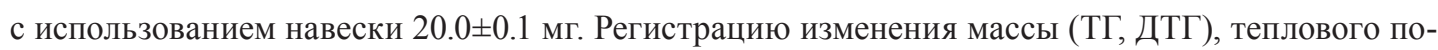
тока (ДСК) и состава газообразных продуктов (по молекулярным ионам $\mathrm{Ar}^{+}, \mathrm{O}_{2}^{+}, \mathrm{CO}_{2}^{+}, \mathrm{CO}^{+}$, $\mathrm{H}_{2} \mathrm{O}^{+}$и $\mathrm{SO}_{2}^{+}$) проводили в режиме линейного подъема температуры со скоростью $10{ }^{\circ} \mathrm{C} /$ мин в диапазоне температур $40-1000{ }^{\circ} \mathrm{C}$ с подачей газовой смеси $20 \% \mathrm{O}_{2}+80 \% \mathrm{Ar}$ (общий поток $50 \mathrm{~cm}^{3}$ НТД/мин). Коэффициент чувствительности сенсора ДСК-ТГ определяли из теплоемкости стандартного сапфирового диска, относительная ошибка определения $\Delta Н$ не превышала $4 \%$.

\section{Результаты и обсуждение}

Исходная ВКЛЗ имеет размеры $d_{90}-10$ мкм и является существенно более дисперсным материалом по сравнению с ПЦ 42.5Н (рис. 1). В химическом составе ВКЛЗ (табл. 1) преобладает $\mathrm{CaO}$ (39.6 мас. \%), при этом содержится достаточно много $\mathrm{SiO}_{2}$ (24.6 мас. \%) и $\mathrm{Fe}_{2} \mathrm{O}_{3}(14.3$ мас. \%). Основные отличия от состава ПЦ $42.5 \mathrm{H}$ - меньшее содержание $\mathrm{CaO}$ и более высокое содержа- 
ние $\mathrm{Al}_{2} \mathrm{O}_{3}, \mathrm{Fe}_{2} \mathrm{O}_{3}$ и $\mathrm{MgO}$. В фазовом составе присутствуют кристаллические Са-содержащие фазы $\mathrm{Ca}_{2} \mathrm{Fe}_{\mathrm{x}} \mathrm{Al}_{\mathrm{y}} \mathrm{O}_{5}-17, \mathrm{Ca}_{3} \mathrm{Al}_{2} \mathrm{O}_{6}-10, \mathrm{CaSO}_{4}-7, \mathrm{CaCO}_{3}-5, \mathrm{CaO}-4$ мас. \% и стеклофаза 42 мас. \% (табл. 2). Наблюдается ряд отличий фазового состава ВКЛЗ от ПЦ $42.5 \mathrm{H}$ - отсутствие фаз силикатов кальция $\mathrm{Ca}_{3} \mathrm{SiO}_{5}$ и $\mathrm{Ca}_{2} \mathrm{SiO}_{4}$, которые в ПЦ составляют 73.7 мас. \%, преобладающим компонентом ВКЛЗ является аморфная фаза (42 мас. \%), содержание клинкерных фаз - трехкальциевый алюминат $3 \mathrm{CaO} \cdot \mathrm{Al}_{2} \mathrm{O}_{3}\left(9.9\right.$ мас. \%) и алюмоферрит кальция $\mathrm{Ca}_{2} \mathrm{Fe}_{\mathrm{x}} \mathrm{Al}_{\mathrm{y}} \mathrm{O}_{5}$ (16.9 мас. \%) - несколько выше и, наконец, в составе ВКЛЗ содержится значительное количество фаз несвязанных оксидов $\mathrm{CaO}, \mathrm{MgO}, \mathrm{SiO}_{2}$, а также $\mathrm{CaCO}_{3}$ и $\mathrm{CaSO}_{4}$ (табл. 2).

На поведение ВКЛЗ в процессе гидратации влияет активность как кристаллических фаз, обладающих самостоятельными вяжущими свойствами $\left(\mathrm{Ca}_{3} \mathrm{Al}_{2} \mathrm{O}_{6}, \mathrm{Ca}_{4} \mathrm{Al}_{2} \mathrm{Fe}_{2} \mathrm{O}_{10}, \mathrm{CaO}, \mathrm{CaSO}_{4}\right)$, так и стекла, содержание которого может составлять от 20 до 87\% [13, 14]. Исследование стеклокристаллических микросфер в высококальциевой летучей золе [15] показало, что содержание $\mathrm{CaO}$ в них может меняться от 0 до 60 мас. \% и при его уменьшении снижается реакционная способность микросфер к растворению в воде и кислотах. С увеличением содержания кальция

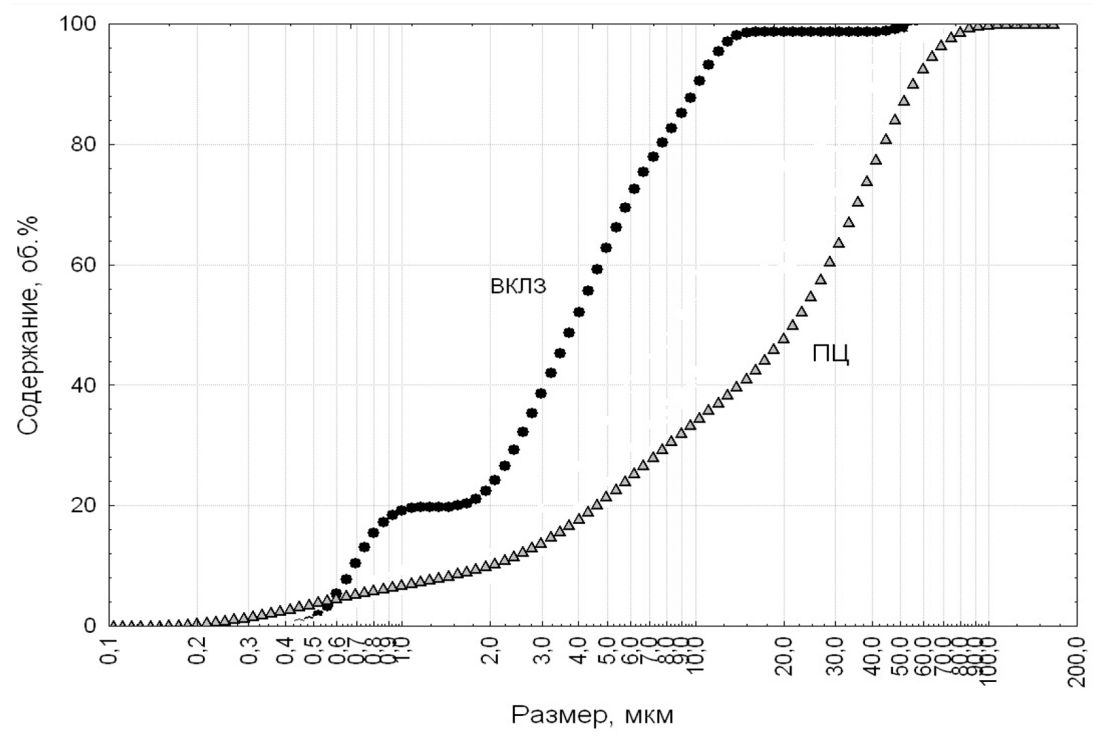

Рис. 1. Распределение по размерам частиц исходной ВКЛЗ и портландцемента ПЦ 42.5Н

Fig. 1. Particle size distribution of the initial HCFA and Portland cement PC $42.5 \mathrm{~N}$

Таблица 1. Химический состав (мас. \%) исходной высококальциевой летучей золы (ВКЛЗ) и портландцемента ПЦ $42.5 \mathrm{H}$ (ПЦ)

Table 1. The chemical composition (wt. \%) of the initial high calcium fly ash (HCFA) and Portland cement PC $42.5 \mathrm{~N}$

\begin{tabular}{|c|c|c|c|c|c|c|c|c|c|c|c|}
\hline \multirow{2}{*}{ Образец } & \multicolumn{10}{|c|}{ Компоненты } \\
\cline { 2 - 15 } & $\mathrm{CaO}$ & $\mathrm{SiO}_{2}$ & $\mathrm{Al}_{2} \mathrm{O}_{3}$ & $\mathrm{Fe}_{2} \mathrm{O}_{3}$ & $\mathrm{MgO}$ & $\mathrm{SO}_{3}$ & $\mathrm{Na}_{2} \mathrm{O}$ & $\mathrm{K}_{2} \mathrm{O}$ & $\mathrm{TiO}_{2}$ & п.п.п. & $\sum$ \\
\hline ВКЛ3 & 39.60 & 24.60 & 7.30 & 14.29 & 8.24 & 2.29 & 0.71 & 0.20 & 0.25 & 1.96 & 99.5 \\
\hline ПЦ & 63.9 & 20.41 & 4.87 & 4.18 & - & 2.46 & - & - & - & - & 95.91 \\
\hline
\end{tabular}


Таблица 2. Фазовый состав (мас. \%) исходной ВКЛ3 и портландцемента ПЦ 42.5Н (ПЦ)

Table 2. The phase composition (wt. \%) of the initial HCFA and Portland cement PC $42.5 \mathrm{~N}$

\begin{tabular}{|c|c|c|c|c|c|c|c|c|c|c|c|c|c|c|}
\hline \multirow[b]{2}{*}{ Образец } & \multicolumn{14}{|c|}{ Фазы } \\
\hline & 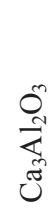 & 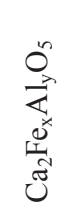 & O্ત & $\sum_{\substack{0 \\
\sum}}^{0}$ & $\begin{array}{c}\delta_{0}^{N} \\
1 \\
0\end{array}$ & 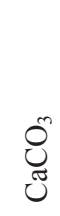 & 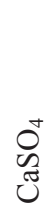 & 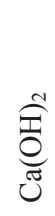 & 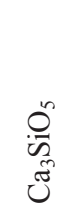 & 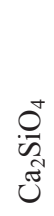 & 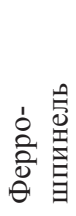 & 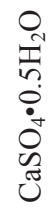 & 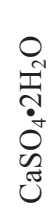 & 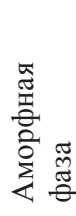 \\
\hline ВКЛЗ & 9.9 & 16.9 & 4.2 & 5.7 & 5.3 & 4.9 & 6.5 & 2.1 & - & - & 2.4 & - & - & 42.1 \\
\hline ПЦ & 5.8 & 13.2 & - & - & 0.5 & 2.4 & - & - & 64.5 & 9.2 & - & 3.9 & 0.5 & - \\
\hline
\end{tabular}

в алюмосиликатных и силикатных стеклах у них появляются самостоятельные вяжущие свойства, которые зависят от величины основности $\mathrm{R}=\mathrm{CaO} / \mathrm{SiO}_{2}$ [16]. В системе $\mathrm{CaO}-\mathrm{Al}_{2} \mathrm{O}_{3}-\mathrm{SiO}_{2}$ при $\mathrm{R}<0.5$ стекла проявляют только пуццоланические свойства; самостоятельные вяжущие свойства улучшаются для стекол с R от 0.5 до 1.3 и лучшие вяжущие свойства имеют стекла $\mathrm{c} \mathrm{R}>1.3$.

В работах $[11,12]$ описан бесцементный композитный материал (КМ), полученный на основе тонкодисперсной ВКЛЗ 4 поля ЭФ Красноярской ТЭЦ-2. В работе [12] приведен состав стекла этой ВКЛЗ, из которого следует, что величина R для него составляет в среднем около 0.8 , следовательно, такие стекла могут проявлять вяжущую активность. Для улучшения пластичности образцов на основе тонкодисперсной ВКЛЗ использован поликарбоксилатный суперпластификатор Melflux 5581F при концентрации 0,12\%, что позволило снизить отношение «вода/цементирующий материал» (В/Ц) до 0.25. Прочность на сжатие образцов КМ возрастала от 17 до 72 МПа при сроках отверждения от 1 до 120 сут. Из этих данных следует, что тонкодисперсная ВКЛЗ может применяться в качестве самостоятельного вяжущего материала и обеспечивать высокую прочность за счет гидратации как гидравлически активных кристаллических фаз, так и активного стекла. Дополнительное регулирование свойств возможно с помощью варьирования концентрации суперпластификатора, а также добавок ускорителей и замедлителей процесса твердения.

\section{Влияние конщентрации суперпластификатора}

На рис. 2 приведены зависимости прочности на сжатие от концентрации суперластификатора Melflux 5581F при разных сроках твердения. Для образцов, приготовленных из тонкодисперсной ВКЛЗ при В/C = 0.4 без добавки суперпластификатора, величина прочности составляет 11, 22 и 30 МПа при сроках твердения 3, 28 и 80 сут соответственно. Для образцов, приготовленных с добавкой суперпластификатора в интервале от 0.06 до 0.6 мас. \% при В/С $=0.25$, кривые проходят через максимум. В частности, при добавке $0.06 \%$ величина прочности возросла до 24, 34 и 58 МПа при сроках твердения 3, 28 и 80 сут соответственно. Максимальное значение прочности наблюдалось при увеличении концентрации суперпластификатора до 0.3\%, которое возросло до $\sim 45,60$ и 78 МПа при сроках твердения 3, 28 и 80 сут соответственно. Пройдя через максимум, дальнейшее повышение концентрации суперпластификатора до 0.6\% приводит 
к уменьшению прочности композитных образцов (рис. 2). В литературе аналогичные результаты объясняются неоднородностью распределения жидкости и твердой фазы вследствие локального расслоения в цементирующих растворах высокой текучести, которая возникает при добавлении высоких концентраций суперпластификатора [3].

Зависимости прочности на сжатие от времени твердения в течение 140 сут изображены на рис. 3, самую низкую величину прочности (11-30 МПа) имеют образцы на основе ВКЛЗ при $\mathrm{B} / \mathrm{C}=0.4$ (рис. 3 , кривая 1). При этом прочность образцов, полученных на основе $100 \%$-го портландцемента ПЦ 42.5Н, в сравнимых условиях в $\sim 2$ раза выше и составляет 24-66 МПа (рис. 3, кривая 2). При добавке суперпластификатора Melflux 5581F с концентрацией 0.12 мас. \% было уменьшено отношение В/C до 0.25, что позволило достичь прочности 24-68 МПа в эти же сроки твердения (рис. 3, кривая 3), которая сопоставима с прочностью образцов на основе ПЦ $42.5 \mathrm{H}$ без добавки суперпластификатора (рис. 3, кривая 2). При увеличении концентрации суперпластификатора до 0.3 мас. \% прочность образцов КМ на основе тонкодисперсной ВКЛЗ возросла до $~ 45-84$ МПа, что значительно превышает прочность образцов на основе цемента (рис. 3, кривая 4).

Melflux 5581F - это поликарбоксилатный суперпластификатор, состоящий из боковых цепочек метоксиполиэтиленгликоля, прикрепленных к основной цепи полиметакриловой кислоты [17]. Механизм диспергирования с помощью Melflux 5581F считается связанным с электростатическими силами отталкивания, создаваемыми карбоксильными функциональными группами (-СОО-) основной цепи на поверхности зерен цемента, и с эффектом стерического затруднения, создаваемым гидрофобными боковыми цепями метоксиполиэтиленгликоля [18]. Эффективное диспергирование тонкодисперсного вяжущего материала способствует более быстрому и полному взаимодействию компонентов при растворении и образовании новых фаз.

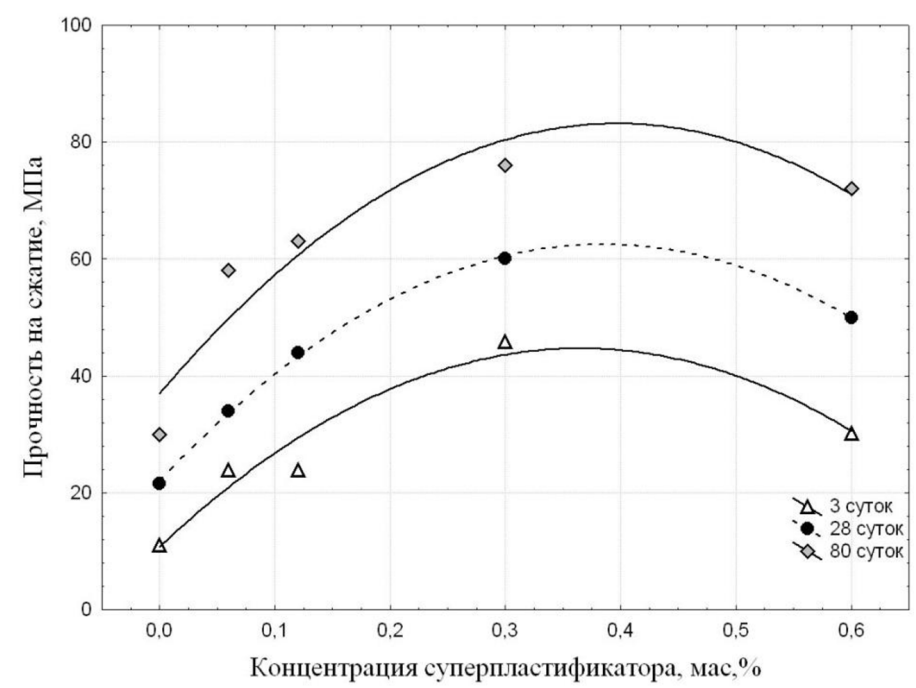

Рис. 2. Зависимость прочности на сжатие от концентрации суперпластификатора Melflux 5581F для композитных образцов на основе тонкодисперсной ВКЛЗ при $\mathrm{B} / \mathrm{C}=0.25$

Fig. 2. The dependence of compressive strength on the concentration of Melflux 5581F superplasticizer for composite samples based on fine-dispersed HCFA at W/B $=0.25$ 


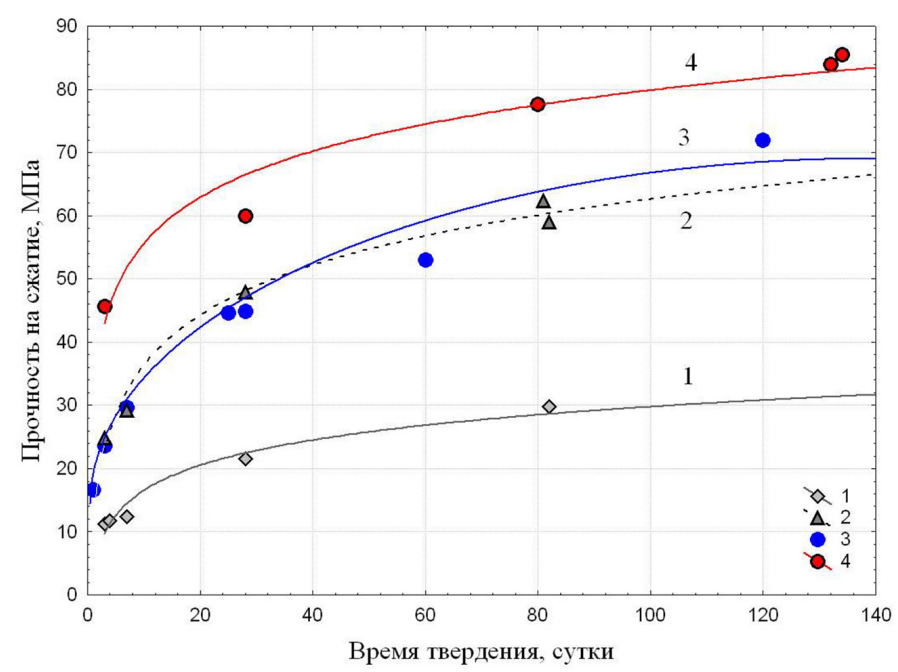

Рис. 3. Зависимость прочности на сжатие от времени твердения для образцов, приготовленных при $\mathrm{B} / \mathrm{C}=0.4$ на основе тонкодисперсной ВКЛЗ (1) и на основе портландцемента ПЦ 42.5 Н (2); при В/C = 0.25 на основе тонкодисперсной ВКЛЗ с добавкой суперпластификатора 0.12 \% (3) и 0.3 \% (4)

Fig. 3. The dependence of compressive strength on hardening time for samples prepared at W/B $=0.4$ based on fine-dispersed HCFA (1) and based on Portland cement PC $42.5 \mathrm{~N}(2)$; at W/B $=0.25$ based on fine-dispersed HCFA with the addition of superplasticizer $0.12 \%$ (3) and $0.3 \%$ (4)

Фазовые превращения в КМ на основе 100\%-го ВКЛЗ детально описаны ранее в работах $[11,12]$, и установлено, что на третьи сутки полностью прореагировали алюмоферрит кальция $\mathrm{Ca}_{2} \mathrm{Fe}_{\mathrm{x}} \mathrm{Al}_{\mathrm{y}} \mathrm{O}_{5}$ и сульфат кальция $\mathrm{CaSO}_{4}$. При этом активно образуются эттрингит $3 \mathrm{CaO} \cdot \mathrm{Al}_{2} \mathrm{O}_{3} \cdot 3 \mathrm{CaSO}_{4} \cdot 32 \mathrm{H}_{2} \mathrm{O}$, карбонат кальция $\mathrm{CaCO}_{3}$, портландит $\mathrm{Ca}(\mathrm{OH})_{2}$. На 28-е сутки твердения наблюдается значительное уменьшение количества $\mathrm{CaCO}_{3}$ и образование гидратов карбоалюминатов кальция $\mathrm{Ca}_{4} \mathrm{Al}_{2}(\mathrm{OH})_{13}\left(\mathrm{CO}_{3}\right)_{0,5} \cdot 4 \mathrm{H}_{2} \mathrm{O}$ и $\mathrm{Ca}_{4} \mathrm{Al}_{2}(\mathrm{OH})_{12} \mathrm{CO}_{3} \cdot 5 \mathrm{H}_{2} \mathrm{O}$ с очень низкой кристалличностью, а также значительно возрастает количество $\mathrm{Ca}(\mathrm{OH})_{2}$ и уменьшается содержание аморфной фазы (табл. 3). Главными новообразованными фазами являются эттрингит $3 \mathrm{CaO} \cdot \mathrm{Al}_{2} \mathrm{O}_{3} \cdot 3 \mathrm{CaSO}_{4} \cdot 32 \mathrm{H}_{2} \mathrm{O}$ и гидраты карбоалюминатов кальция $\mathrm{Ca}_{4} \mathrm{Al}_{2}(\mathrm{OH})_{13}\left(\mathrm{CO}_{3}\right)_{0,5} \cdot 4 \mathrm{H}_{2} \mathrm{O}$ и $\mathrm{Ca}_{4} \mathrm{Al}_{2}(\mathrm{OH})_{12} \mathrm{CO}_{3} \cdot 5 \mathrm{H}_{2} \mathrm{O}$ с низкой кристалличностью, а также скрытокристаллические гидросиликаты кальция, тонкая смесь которых создает высокую прочность композитного материала в процессе гидратационного твердения.

\section{Влияние сульфата натрия}

Одной из добавок-активаторов гидратации является сульфат натрия $\mathrm{Na}_{2} \mathrm{SO}_{4}$. Например, применение в качестве активатора 3-4\% $\mathrm{Na}_{2} \mathrm{SO}_{4}$ способствует увеличению активности алюмосиликатного стекла летучей золы и кальцийалюмосиликатного стекла доменного шлака в смеси с $\mathrm{CaO}$ в соотношении Л3 $: \mathrm{CaO}=80: 20$ и Л3 : Шлак : $\mathrm{CaO}=60: 27: 13$, а также в смеси Л3 с ПЦ (30:70) [19] и Л3 : ПЦ $=80: 20$ [20]. С добавлением $\mathrm{Na}_{2} \mathrm{SO}_{4}$ протекает его реакция $\mathrm{c} \mathrm{Ca}(\mathrm{OH})_{2}$, в результате которой возрастает $\mathrm{pH}$ раствора, что увеличивает растворение зольного и шлакового стекол и скорость пуццоланических реакций с образованием гидросиликатов и гидроалюмосиликатов кальция. Кроме того, возрастает количество гидрата $\mathrm{CaSO}_{4} \bullet \mathrm{xH}_{2} \mathrm{O}$, 
Таблица 3. Фазовый состав (мас. \%) исходной ВКЛЗ и композитных образцов на ее основе с $0.12 \%$ Melflux $5581 \mathrm{~F}$ при $\mathrm{B} / \mathrm{C}=0.25$ без добавки и с добавкой $5 \% \mathrm{Na}_{2} \mathrm{SO}_{4}$ после 28 сут твердения

Table 3. The phase composition (wt. \%) of the initial HCFA and composite samples based on it with $0.12 \%$ Melflux $5581 \mathrm{~F}$ at W/B $=0.25$ without additives and with the addition of $5 \% \mathrm{Na}_{2} \mathrm{SO}_{4}$ after 28 days of hardening

\begin{tabular}{|c|c|c|c|}
\hline Фаза & Исходная ВКЛЗ & $\begin{array}{c}28 \text { сут } \\
{[12]}\end{array}$ & $\begin{array}{c}28 \text { сут } \\
\left(5 \% \mathrm{Na}_{2} \mathrm{SO}_{4}\right)\end{array}$ \\
\hline \multicolumn{4}{|c|}{ Кристаллические фазы } \\
\hline $\mathrm{Ca}_{2} \mathrm{Fe}_{\mathrm{x}} \mathrm{Al}_{\mathrm{y}} \mathrm{O}_{5}$ & 16.9 & - & - \\
\hline $\mathrm{Ca}_{3} \mathrm{Al}_{2} \mathrm{O}_{6}$ & 9.9 & 8.1 & 8.7 \\
\hline $\mathrm{CaSO}_{4}$ & 6.5 & - & - \\
\hline $\mathrm{MgO}$ & 5.7 & 4.0 & 4.7 \\
\hline a-SiO 2 (кварц) & 5.3 & 5.7 & 5.6 \\
\hline $\mathrm{CaCO}_{3}$ & 4.9 & 2.1 & 2.8 \\
\hline $\mathrm{CaO}$ & 4.2 & 2.3 & 2.4 \\
\hline Феррошпинель & 2.4 & 2.7 & 2.9 \\
\hline $\mathrm{Ca}(\mathrm{OH})_{2}$ & 2.1 & 9.6 & 5.9 \\
\hline $\begin{array}{l}\mathrm{Ca}_{6} \mathrm{Al}_{2}\left(\mathrm{SO}_{4}\right)_{3}(\mathrm{OH})_{12} \cdot 26 \mathrm{H}_{2} \mathrm{O} \\
\text { (эттрингит) }\end{array}$ & - & 12.4 & 13.4 \\
\hline $\mathrm{Ca}_{2} \mathrm{SiO}_{4}$ (ларнит) & - & 3.4 & 3.3 \\
\hline$\Sigma$ & 57.9 & 50.3 & 49.7 \\
\hline \multicolumn{4}{|c|}{ Слабоокристаллизованные и аморфная фазы } \\
\hline $\mathrm{Ca}_{4} \mathrm{Al}_{2}(\mathrm{OH})_{13}\left(\mathrm{CO}_{3}\right)_{0.5} \bullet 4 \mathrm{H}_{2} \mathrm{O}$ & - & 14.1 & 3.6 \\
\hline $\mathrm{Ca}_{4} \mathrm{Al}_{2}(\mathrm{OH})_{12} \mathrm{CO}_{3} \cdot 5 \mathrm{H}_{2} \mathrm{O}$ & - & 5.3 & - \\
\hline Аморфная фаза & 42.1 & 30.3 & 46.7 \\
\hline$\Sigma$ & 42.1 & 49.7 & 50.3 \\
\hline Прочность на сжатие, МПа & - & 45 & 49 \\
\hline
\end{tabular}

приводящего к образованию дополнительного эттрингита. В совокупности эти процессы способствовали увеличению прочности [19, 20].

В табл. 3 приведены данные по фазовому составу и прочности КМ на основе тонкодисперсной ВКЛЗ, полученных при В/C $=0.25$, концентрации суперпластификатора 0.12 мас. \% без добавки и с добавкой 5 мас. \% $\mathrm{Na}_{2} \mathrm{SO}_{4}$. Из этих данных следует, что содержание эттрингита увеличилось от 12.4 до 13.4 мас. \%. Более значительные изменения наблюдаются в превращении гидратов карбоалюминатов - исчезла фаза монокарбоалюмината $\mathrm{Ca}_{4} \mathrm{Al}_{2}(\mathrm{OH})_{12} \mathrm{CO}_{3} \cdot 5 \mathrm{H}_{2} \mathrm{O}$ и уменьшилась от 14.1 до 3.6 мас. \% фаза полукарбоалюмината $\mathrm{Ca}_{4} \mathrm{Al}_{2}(\mathrm{OH})_{13}\left(\mathrm{CO}_{3}\right)_{0.5} \bullet 4 \mathrm{H}_{2} \mathrm{O}$, а также - в увеличении количества аморфной фазы от 30.3 до 46.7 мас. \%. При этом прочность отвержденных образцов несколько увеличилась (от 45 до 49 МПа). Наиболее вероятным результатом этих превращений является образование аморфных фаз моносульфоалюмината $3 \mathrm{CaO} \cdot \mathrm{Al}_{2} \mathrm{O}_{3} \cdot \mathrm{CaSO}_{4} \cdot 12 \mathrm{H}_{2} \mathrm{O}$ и фаз $\mathrm{AFm}$ общего состава $\left[\mathrm{Ca}_{2}(\mathrm{Al}, \mathrm{Fe})(\mathrm{OH})_{6}\right] \cdot \mathrm{X} \cdot \mathrm{xH}_{2} \mathrm{O}$, где в качестве $\mathrm{X}$ могут быть анионы $\mathrm{OH}^{-}, \mathrm{SO}_{4}{ }^{2-}$ и $\mathrm{CO}_{3}^{2-}$, содержащих меньшее количество воды по сравнению с эттрингитом [5].

Из данных синхронного термического анализа (СТА) также следует, что при добавлении $5 \% \mathrm{Na}_{2} \mathrm{SO}_{4}$ на кривых ТГ, ДТГ, ДСК наблюдаются видимые изменения, включая уменьшение

$$
-403-
$$




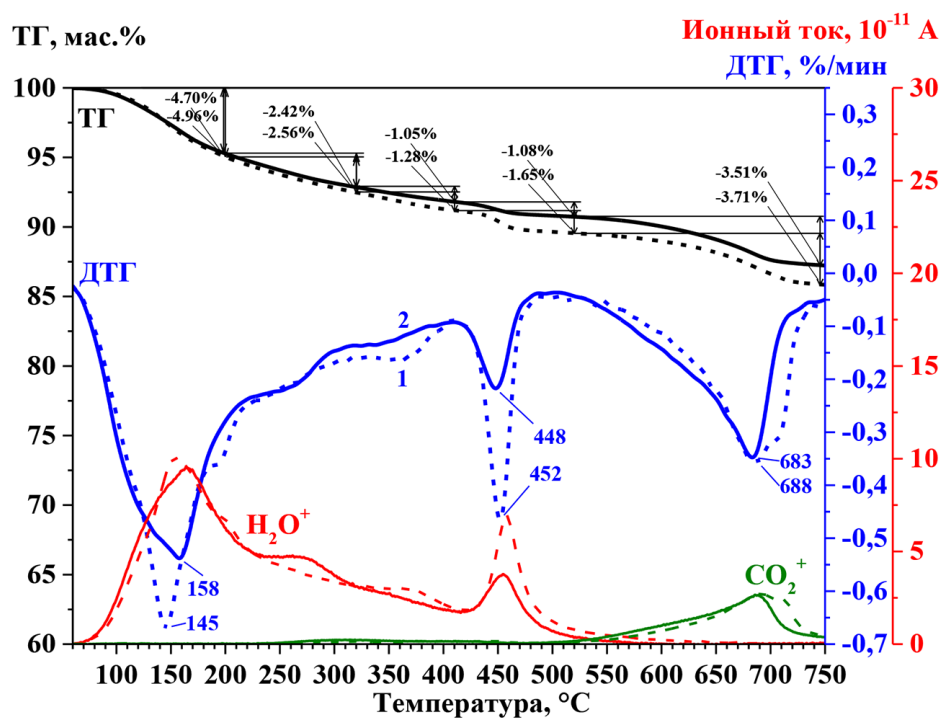

Рис. 4. Данные СТА (ТГ/ДТГ и масс-спектры $\mathrm{H}_{2} \mathrm{O}$ и $\mathrm{CO}_{2}$ ) для образцов, приготовленных на основе тонкодисперсной ВКЛЗ при $\mathrm{B} / \mathrm{C}=0.25$ с добавкой суперпластификатора 0.12 мас. \% (1) и дополнительной добавкой $5 \% \mathrm{Na}_{2} \mathrm{SO}_{4}(2)$ при времени твердения 28 сут

Fig. 4. STA data (TG / DTG and mass spectra of $\mathrm{H}_{2} \mathrm{O}$ and $\mathrm{CO}_{2}$ ) for samples prepared on the basis of fine-dispersed $\mathrm{HCFA}$ at $\mathrm{W} / \mathrm{B}=0.25$ with the addition of superplasticizer $0.12 \mathrm{wt} . \%$ (1) and additional addition of $5 \% \mathrm{Na}_{2} \mathrm{SO}_{4}$ (2) at the time of hardening 28 days

потерь массы во всех обозначенных интервалах температур (рис. 4) в 1.1-1.2 раза, которые означают различия в составе гидратных фаз. В частности, исчезновение точек перегиба при 195 и $362{ }^{\circ} \mathrm{C}$ в образце с $\mathrm{Na}_{2} \mathrm{SO}_{4}$ связано с уменьшением содержания гидратов карбоалюминатов. Снижение массы в 1.5 раза наблюдалось в интервале дегидратации $\mathrm{Ca}(\mathrm{OH})_{2}\left(410-520{ }^{\circ} \mathrm{C}\right)$, что согласуется с данными РФА (табл. 3) и означает активирующее действие $\mathrm{Na}_{2} \mathrm{SO}_{4}$ на степень превращения $\mathrm{Ca}(\mathrm{OH})_{2}$ по сравнению с бездобавочным образцом.

\section{Влияние добавок-замедлителей}

Самым лучшим неорганическим замедлителем для цемента является трифосфат натрия $\mathrm{Na}_{3} \mathrm{PO}_{4}[8]$. Он адсорбируется на поверхности частиц цемента и первых продуктов гидратации, образуя защитный слой фосфата кальция. Однако в случае ВКЛ3 добавка 1\% $\mathrm{Na}_{3} \mathrm{PO}_{4}$, напротив, ускоряет схватывание, что приводит к быстрой потере пластичности цементирующей композиции. Уменьшение концентрации $\mathrm{Na}_{3} \mathrm{PO}_{4}$ до 0.2 мас. \% не дало ожидаемого эффекта. По-видимому, высокая плотность отрицательного заряда аниона $\mathrm{PO}_{4}{ }^{3-}$ обеспечивает его более высокую активность по сравнению с карбоксильными функциональными группами (-СОО-) суперпластификатора при взаимодействии с поверхностью зольных микросфер.

Известными добавками-замедлителями являются также тетраборат натрия $\mathrm{Na}_{2} \mathrm{~B}_{4} \mathrm{O}_{7}$ и лимонная кислота $\mathrm{C}_{6} \mathrm{H}_{8} \mathrm{O}_{7}[6,7]$. Даже при близком химическом составе и относительно небольших отличиях в фазовом составе для ВКЛЗ разных источников наблюдались радикальные отличия в составе поровых растворов, особенно в содержании ионов $\mathrm{SO}_{4}^{2-}, \mathrm{Ca}^{2+}$ и $\mathrm{Na}^{+}$и в со- 
отношении образующихся гидратных фаз - эттрингита $6 \mathrm{CaO} \cdot \mathrm{Al}_{2} \mathrm{O}_{3} \cdot\left(\mathrm{SO}_{4}\right)_{3} \cdot 32 \mathrm{H}_{2} \mathrm{O}$, моносульфоалюмината кальция $4 \mathrm{CaO} \cdot \mathrm{Al}_{2} \mathrm{O}_{3} \cdot \mathrm{SO}_{4} \cdot 12 \mathrm{H} 2 \mathrm{O}$, стратлингита $2 \mathrm{CaO} \cdot \mathrm{Al}_{2} \mathrm{O}_{3} \cdot \mathrm{SiO}_{2} \cdot 8 \mathrm{H}_{2} \mathrm{O}$ [14, 21$]$. Видимо, как результат влияния этих факторов для высококальциевых зол с 15 теплоэлектростанций США, близких по химическому составу (содержание СаО варьируется от 26 до 28\%), показано, что прочность на 28 -е сут отличалась на порядок (от 3 до 30 МПа) и наблюдалось противоречивое влияние добавки тетрабората натрия, предназначенной для регулирования твердения [22].

Испытания композитных образцов на основе тонкодисперсной ВКЛЗ с добавкой $1 \%$ $\mathrm{Na}_{2} \mathrm{~B}_{4} \mathrm{O}_{7}$ увеличивает время схватывания в 6 раз, при этом прочность на сжатие образцов на 106-е сутки уменьшается на $12 \%$ по сравнению с бездобавочным образцом. Очень сильное замедляющее действие наблюдалось при добавке $1 \% \mathrm{C}_{6} \mathrm{H}_{8} \mathrm{O}_{7}$ (время схватывания больше в 90 раз), при этом прочность образцов на 86-е сутки была ниже на 16\% относительно образца сравнения. Эффективное регулирование времени схватывания было при концентрации $\mathrm{C}_{6} \mathrm{H}_{8} \mathrm{O}_{7}$ в интервале 0.1-0.3 мас. \%, в котором обеспечивается увеличение времени схватывания в 2.520 раз при снижении прочности образцов менее $10 \%$.

\section{Заключение}

Для композитного материала на основе тонкодисперсной ВКЛЗ исследовано влияние концентрации суперпластификатора Melflux 5581F на величину прочности на сжатие в интервале от 0.06 до 0.6 мас. \%. Установлено, что лучшими прочностными характеристиками 45-84 МПа при различных временах твердения обладает композитный материал, полученный с добавкой 0.3 мас. \% суперпластификатора Melflux 5581F при низком соотношении $\mathrm{B} / \mathrm{C}=0,25$, что существенно превышает значения прочности на сжатие 24-66 МПа для образцов на основе портландцемента ПЦ $42.5 \mathrm{H}$.

Изучено влияние добавок активаторов и замедлителей. Установлено, что при добавке 5\% $\mathrm{Na}_{2} \mathrm{SO}_{4}$ возрастает активность превращения $\mathrm{Ca}(\mathrm{OH})_{2}$, значительно изменяется состав слабоокристаллизованных и аморфных продуктов, что несколько увеличивает прочность композитов. Изучено действие добавок-замедлителей $\mathrm{Na}_{3} \mathrm{PO}_{4}, \mathrm{Na}_{2} \mathrm{~B}_{4} \mathrm{O}_{7}$ и $\mathrm{C}_{6} \mathrm{H}_{8} \mathrm{O}_{7}$, среди которых $\mathrm{Na}_{3} \mathrm{PO}_{4}$ не имеет эффекта для композитного материала на основе тонкодисперсной ВКЛЗ с добавкой суперпластификатора Melflux 5581F. Установлено, что наиболее эффективное регулирование замедления оказывает $\mathrm{C}_{6} \mathrm{H}_{8} \mathrm{O}_{7}$ (лимонная кислота) в интервале концентраций 0.1-0.3 мас. \% при снижении прочности образцов примерно на $10 \%$.

\section{Благодарности / Acknowledgements and Funding}

Авторы выражают благодарность сотруднику ИХХТ СО РАН В.В. Юмашеву за выполнение синхронного термического анализа образцов композитного материала. Работа выполнена в рамках государственного задания Института химии и химической технологии СО РАН (проект АААА-А17-117021310222-4) с использованием оборудования Красноярского регионального центра коллективного пользования ФИЦ КНЦ СО РАН.

We are grateful to staff members of the Institute of Chemistry and Chemical Technology of the Siberian Branch of the Russian Academy of Sciences (Krasnoyarsk) V.V. Yumashev for performing the simultaneous thermal analysis analysis.

$$
-405-
$$


The study was performed at the Institute of Chemistry and Chemical Technology, Siberian Branch, Russian Academy of Sciences within the framework of a state contract (AAAA-A17-117021310222-4) using the equipment of the Krasnoyarsk regional center of collective use of FRC KSC SB RAS.

\section{Список литературы / References}

1. Межгосударственный стандарт ГОСТ 24211-2008 Добавки для бетонов и строительных растворов. Общие технические условия. Москва: Стандартинформ, 2010. 16 с. [Interstate standard GOST 24211-2008. Admixtures for concretes and mortars. General specifications. Moscow: Standartinform, 2010. 16 p. (In Russ.)]

2. Lange A., Plank J. Contribution of non-adsorbing polymers to cement dispersion. Cement and Concrete Research 2016. Vol. 79, P. 131-136.

3. Li Z. Advanced concrete technology. New Jersey: Wiley \& Sons, 2011. 506 p.

4. Yoshioka K., Tazawa E., Kawai K., Enohata T. Adsorption characteristics of superplasticizers on cement component minerals. Cement and Concrete Research 2002. Vol. 32, P. 1507-1513.

5. Taylor H.F.W. Cement Chemistry, 2nd Edition. London: Tomas Telford, 1997. 476 p.

6. Lee T., Lee J., Kim Y. Effects of admixtures and accelerators on the development of concrete strength for horizontal form removal upon curing at $10{ }^{\circ} \mathrm{C}$. Construction and Building Materials 2020. Vol. 237, article 117652.

7. Бутт Ю.М., Сычев М.М., Тимашев В.В. Химическая технология вяжущих материалов. Москва: Высшая школа, 1980. 472 c. [Butt Yu.M., Sychev M.M., Timashev V.V. Chemical technology of binders. Moscow: Higher school, 1980.472 c. (In Russ.)]

8. Zhang Y., Yang J., Cao X. Effects of several retarders on setting time and strength of building gypsum. Construction and Building Materials 2020. Vol. 240, article 117927.

9. Azimi-Pour M., Eskandari-Naddaf H., Pakzad A. Linear and non-linear SVM prediction for fresh properties and compressive strength of high volume fly ash self-compacting concrete. Construction and Building Materials 2020. Vol. 230, article 117021.

10. Yu J., Lu C., Leung Ch. K.Y., Li G. Mechanical properties of green structural concrete with ultrahigh-volume fly ash. Construction and Building Materials 2017. Vol. 147, P. 510-518.

11. Sharonova O.M., Yumashev V.V., Solovyov L.A., Anshits A.G. The fine high-calcium fly ash as the basis of composite cementing material. Magazine of Civil Engineering 2019. Vol. 91(7), P. $60-72$.

12. Sharonova O.M., Kirilets V.M., Yumashev V.V., Solovyov L.A., Anshits A.G. Phase composition of high strength binding materials based on fine microspherical high-calcium fly ash, Construction and Building Materials 2019. Vol. 216, P. 525-530.

13. Акимочкина Г.В., Роговенко Е.С., Фоменко Е.В. Определение сопротивления раздавливанию и кислотостойкости узких фракций микросфер летучих зол как основы композитных материалов. Журн. Сиб. федер. ун-та. Химия 2020. 13(2). С. 189-200. [Akimochkina G.V., Rogovenko E.S., Fomenko E.V. Crush and acid resistance of microsphere narrow fractions fromfly ash as the basis of composite materials, J. Sib. Fed. Univ. Chem., 2020, 13(2), P. 189-200 (In Russ.)].

14. Tishmark J.K., Olek J., Diamond S., Sahu S. Characterization of pore solutions expressed from high-calcium fly-ash-water pastes. Fuel 2001. Vol. 80, P. 815-819.

$$
-406-
$$


15. Zhao Y., Zhang J., Tian C., Li H., Shao X., Zheng C. Mineralogy and chemical composition of high-calcium fly ashes and density fractions from a coal-fired power plant in China. Energy and Fuels 2010. 24(2). P. 834-843.

16. Sharonova O. M., Solovyov L.A., Oreshkina N.A., Yumashev V.V., Anshits A.G. Composition of high-calcium fly ash middlings selectively sampled from ash collection facility and prospect of their utilization as component of cementing materials. Fuel Processing and Technology 2010. Vol. 91(6), P. 573-581.

17. Fediuk R.S, Timokhin R.A., Mochalov A.V., Otsokov K.A, Lashina I.V. Performance properties of high-density impermeable cementitious paste, Journal of Materials in Civil Engineering 2019. Vol. 31(4), 04019013.

18. Ferrari L., Kaufmann J., Winnefeld F., Plank J. Multi-method approach to study influence of superplasticizers on cement suspensions, Cement and Concrete Research 2011, Vol. 41, P. 1058-1066.

19. Jueshia Q., Caijun S., Zhi W. Activation of blended cements containing fly ash. Cement and Concrete Research 2001. Vol. 31, P. 1121-1127.

20. Donatello S., Fernandez-Jimenez A., Palomo A. Very high volume fly ash cements. Early age hydration study using $\mathrm{Na}_{2} \mathrm{SO}_{4}$ as an activator. Journal of the American Ceramic Society 2013. Vol. 96, P. 900-906.

21. Huang X., Wang F., Hu S., Lu Y., Rao M., Mu Y. Tishmark J.K., Olek J., Diamond S. Brownmillerite hydration in the presence of gypsum: The effect of $\mathrm{Al} / \mathrm{Fe}$ ratio and sulfate ions. Journal of the American Ceramic Society 2018. Vol. 102, P. 5545-5554.

22. Roskos C., Cross D., Berry M., Stephens J. Identification and verification of self-cementing fly ash binder for "Green" concrete, Proc. 2011 World of Coal Ash (WOCA) conference, 9-12 May, 2011. Denver, USA. 